\title{
Web Mining Intelligent Agents (WEBMINTEL) System
}

\author{
Shakti Kundu and M L Garg \\ Department of Computer Science \& Engineering, \\ DIT University, Dehradun - 248009, Uttarakhand, India. \\ shaktikundu@gmail.com,mlgarg2000@yahoo.com
}

\begin{abstract}
System refers to an orderly grouping of interdependent components linked together according to a plan to achieve a specific objective or goal. Agents require a common agent communication language (ACL) to describe and process agent's requests. Web Mining Intelligent Agents System is built on software program in Java Application Development Environment whose purpose is to extract the relevant information from the large amounts of web data and provide it to the user in a timely manner. Software Agents can assist people in searching and save time. This paper highlights the working of Web Mining Intelligent Agents (WEBMINTEL) System.
\end{abstract}

Keywords: Agents; Intelligent; Systems; Web Mining.

\section{Introduction and Motivation for Research}

Web Data Mining or Data Mining in e-commerce is a rapidly growing field, the development of which is driven by the explosive growth of online information and the economic need to provide personalized products and services. Although data mining applications have been around for several decades, e-commerce provides new issues and new challenges for the field.

Web Mining systems are able to collect data which otherwise are difficult or costly to access and are able to keep track of customer actions in virtual stores, that is, What articles they look at ?, How they browse a catalog ?, What kind of items they put into their shopping cart?

Intelligent Agents refers to calculating entity with characteristics such as independence, duration to perform some set of functions. They assist users to retain some knowledge or information as per user point of view in a timely manner [1]. Intelligent Agents may be defined as computer program that helps a user with routine computer tasks. Other Names of Intelligent Agent are Software Agents, Intelligent Software Robots, Softbots, Bots.

An important advantage of web data mining or e-commerce data mining is the possibility of conducting controlled experiments and measuring their effects on business goals. Direct marketing, for example, can target particular groups, and the results can be data mined for predictive behavior modeling of consumers [2]. Though the existing data mining systems have advantages of their own, yet they are not so perfect enough concerning the intelligence aspect, and still need to be perfected. The Agents play high quality intelligence role in the field of Web Data Mining. The combination of the Agent and Data Mining systems can realize the whole intellectuality of mining process [3].

Agents are well suited for developing Web Mining Systems. The relationship between Agent and e-commerce can be found easily from Agent's characteristics. From the enduser perspective, an Agent is a program that assists people and acts on their behalf [4].

Web Data Mining Agent is a software program built for the primary purpose of finding the information efficiently that operates on a data store. This type of agent is able to detect both major trend changes and new trends [5]. 


\subsection{Web Mining Intelligent Agents (WEBMINTEL) System}

WEBMINTEL System is a collection of various Agents. Multi-Agent system (MAS) is a powerful paradigm in now a day's distributed systems. In Multi-Agent environments, Agents often need to interact in order to achieve their objectives or improve their performance. If Agents are to negotiate automatically with one another they must share a negotiation mechanism [6].

Multi-Agent System is a system composed of many agents, and generally these agents exchange information through network infrastructure. In MAS, the ability of an individual agent is limited, but multi-agent system can finish a lot of complicated tasks through cooperation [7]. MAS can improve enterprises capability to mine customer's information effectively, which can basically helps in saving time and energy.

In WEBMINTEL System, Multi-Agent System performs tasks such as the Registration Agent works for collecting information in cluster form. The User Agent acts as an interface between Registration Agent and Buyer as well as Seller Agent. Session Agent focuses on the user information which is further preceded to the Management agent. Item Agent searches the relevant information for negotiation both from buyer as well as seller standpoints. Negotiation Agent dispatches the information related to negotiation via internet. Besides this it analyze offer in three different ways, namely, Reject, Accept or Give up. If it is Reject, then no further result or information will be delivered whereas if it is Accept, then decision or result in the form of an information will be stored in history record which is finally stored in the related database. Data Mining Agent performs various activities at back end such as Form Editing and managing Field Types and Result Grid.

\subsection{Roadmap}

The remainder of the paper is organized as follows: In the subsequent section, Section 2 describes the front end interface of Web Mining Intelligent Agents (WEBMINTEL) System which was implemented in NetBeans IDE 8.0 platform. Section 3 describes the back end interface of Web Mining Intelligent Agents (WEBMINTEL) System which was created in MySQL Workbench 6.1 platform and finally some conclusions are provided in the Section 4. 


\section{The Front End Interface of Web Mining Intelligent Agents (WEBMINTEL) System}

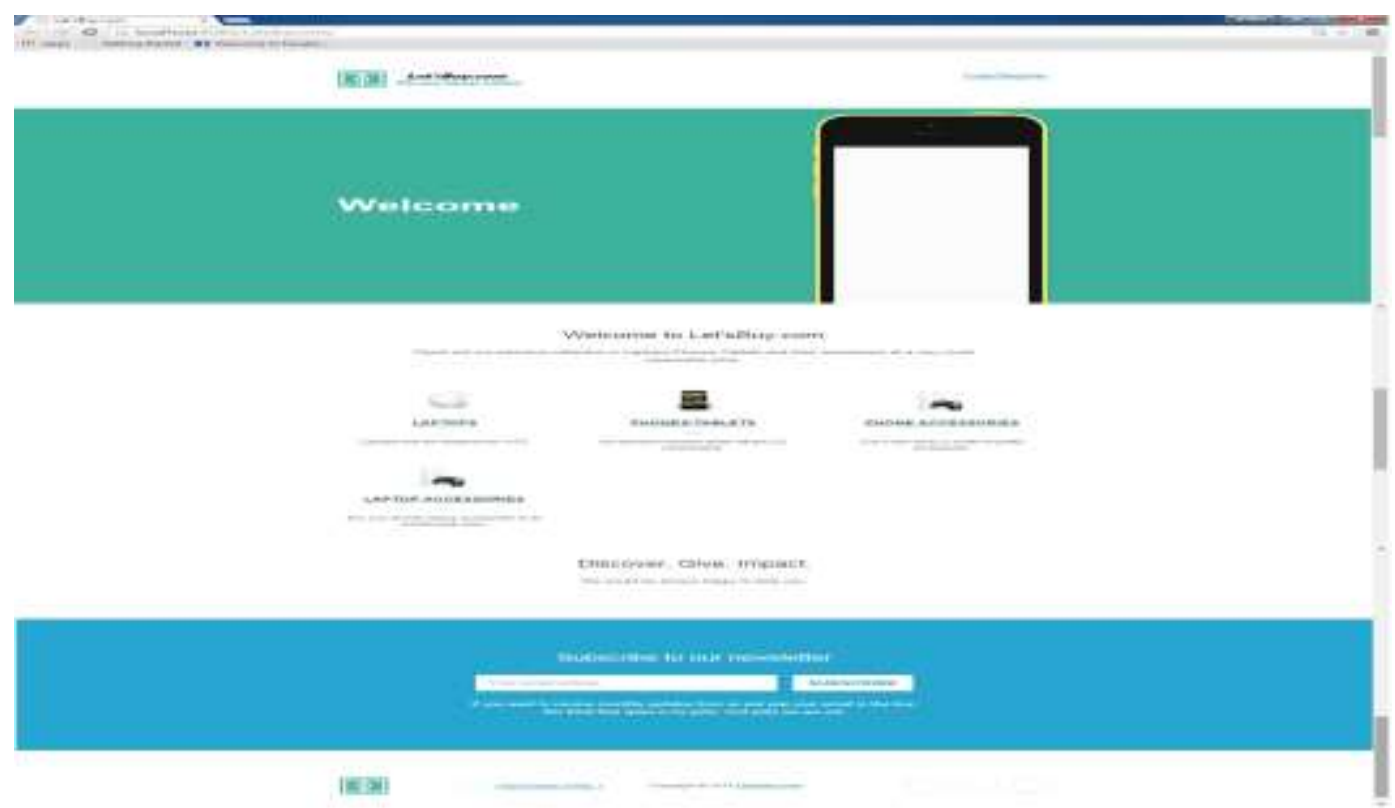

Figure 1. Layout of WEBMINTEL System

Figure 1 discusses the Layout of WEBMINTEL System which highlights the shopping website LetsBuy.com in which an opportunity is provided both for Buyer and Seller to do their respective activities on web based platform. Buyer Agent plays the role of reflecting buying behavior of customers or users and Seller Agent highlights the overall environment of e-commerce.

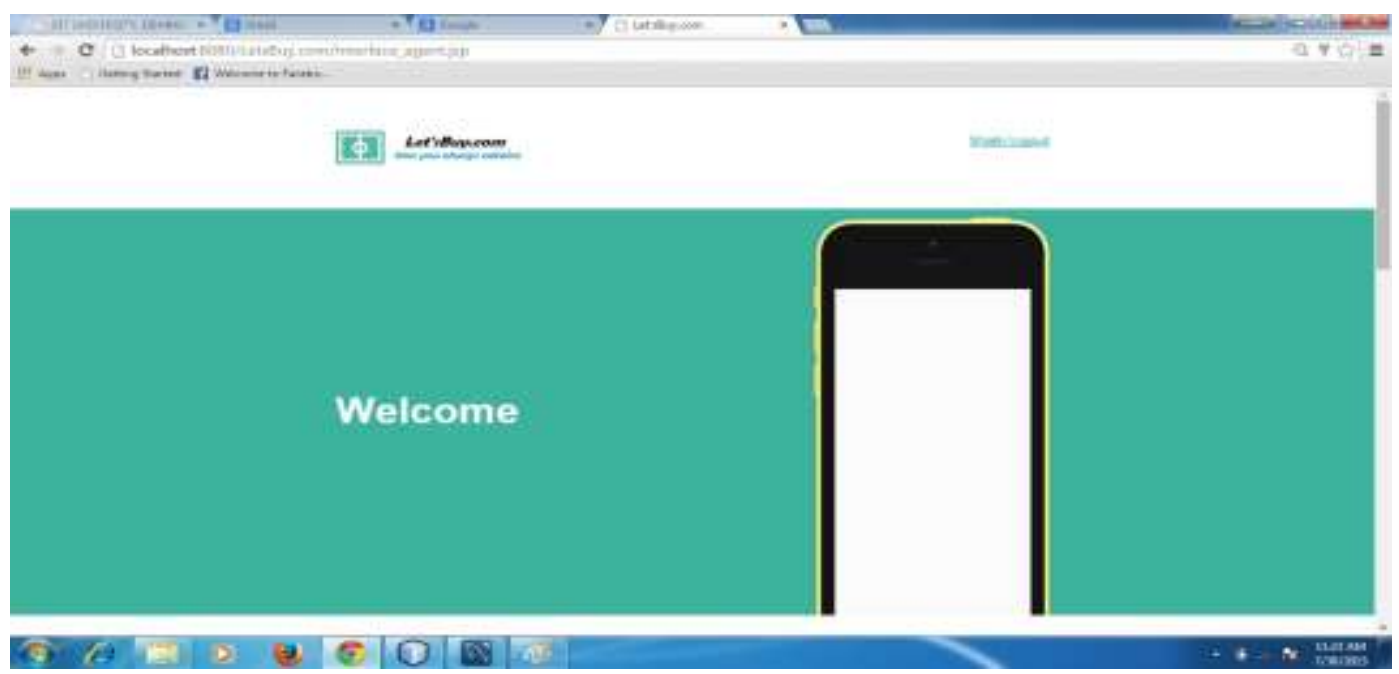

Figure 2. Homepage of LetsBuy Website

Figure 2 discusses the homepage screen of LetsBuy website in which some general tabs are available such as Logo of website, Login / Register and an overview of various available products. 

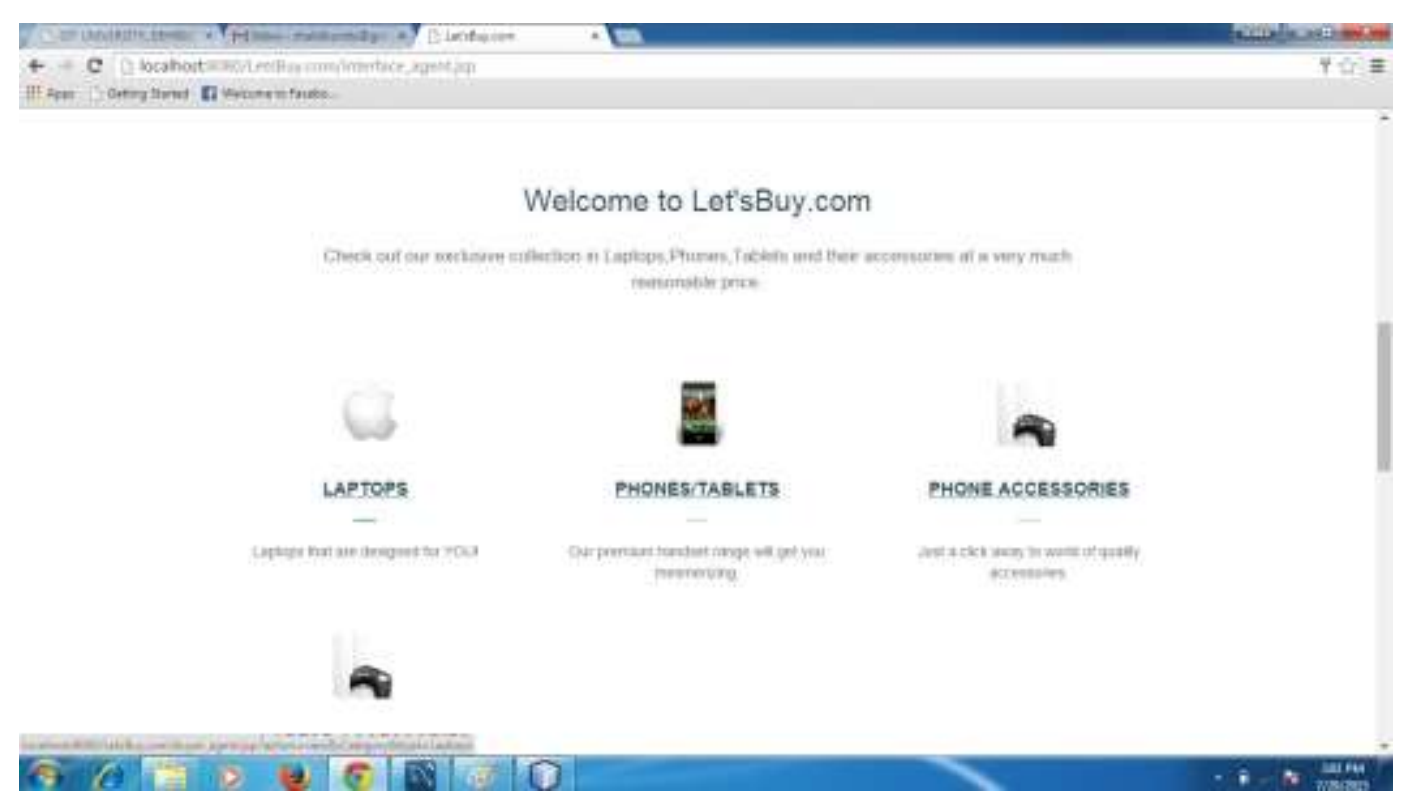

Figure 3. Snapshot of Electronic Gadgets

Figure 3 discusses the snapshot of electronic gadgets such as Laptops, Phones, Tablets, Phone Accessories etc. which highlights the various collections of products. The product details available on the website help the user in making a relevant decision more easily and comfortably.

[is]
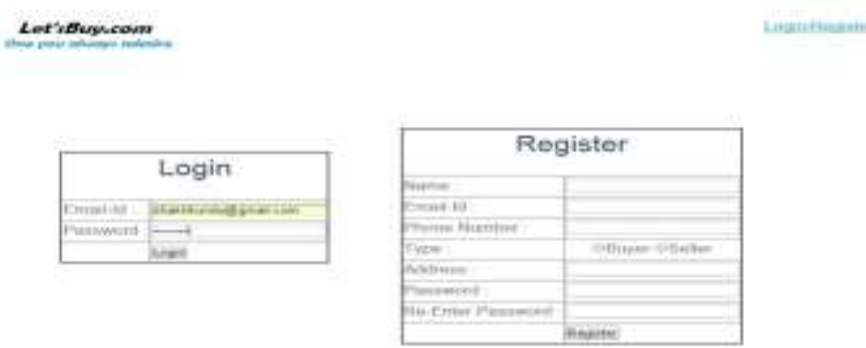

KF.

\section{Figure 4. Login and Register Screen both for Buyer as well as Seller}

Figure 4 discusses the Login and Register Screen both for Buyer as well as Seller. For the first time visit, user has to register while filling the form available on the website with some details such as Name, Email-Id, Phone Number, Type, Address, Password and ReEnter Password. Once the relevant details had been filled by the user he will be able to login with their respective Email-Id and password. 


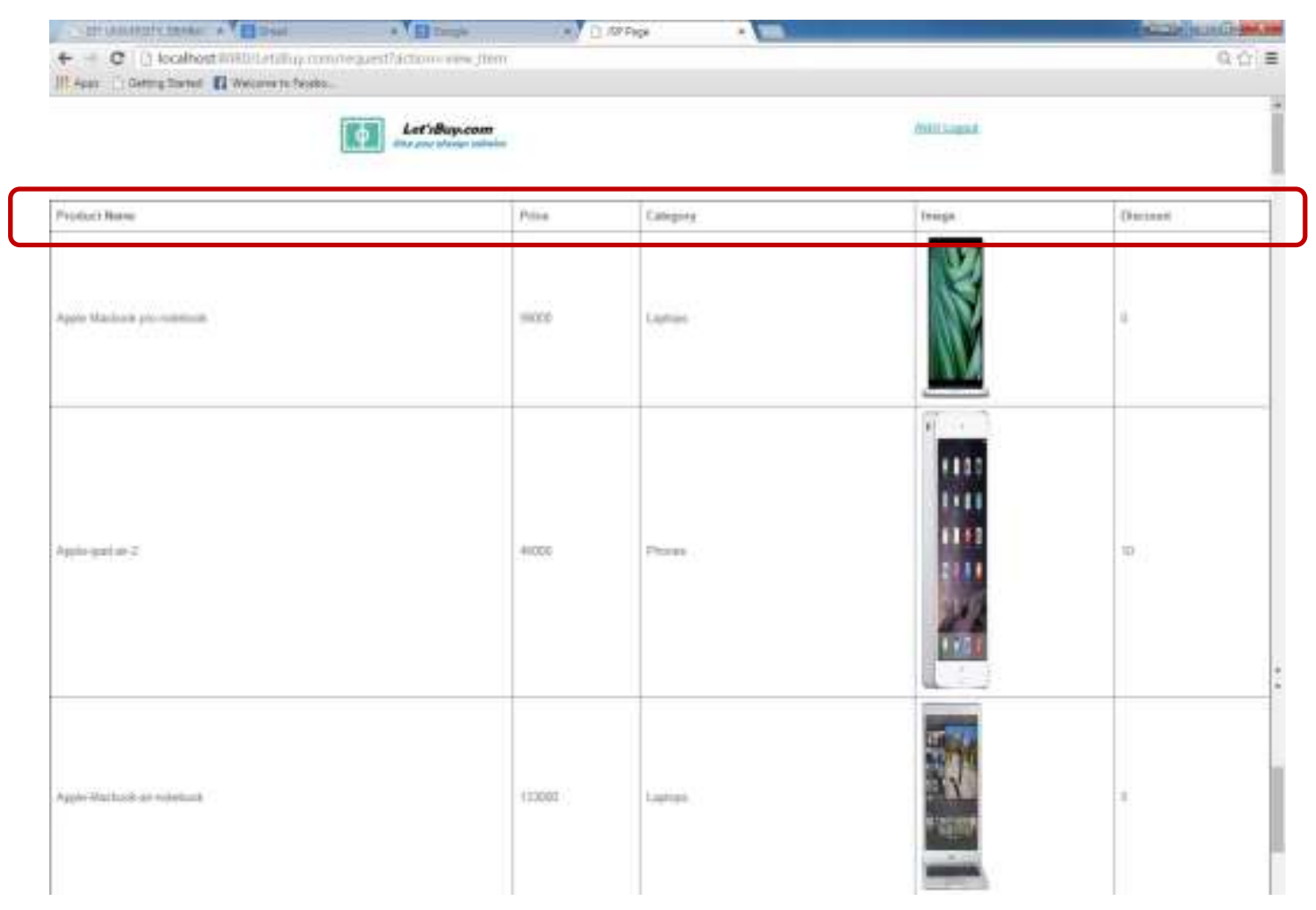

Figure 5. Snapshot of Products

Figure 5 discusses the information of products such as Product Name, Price, Category of product, Product Image and available discount.

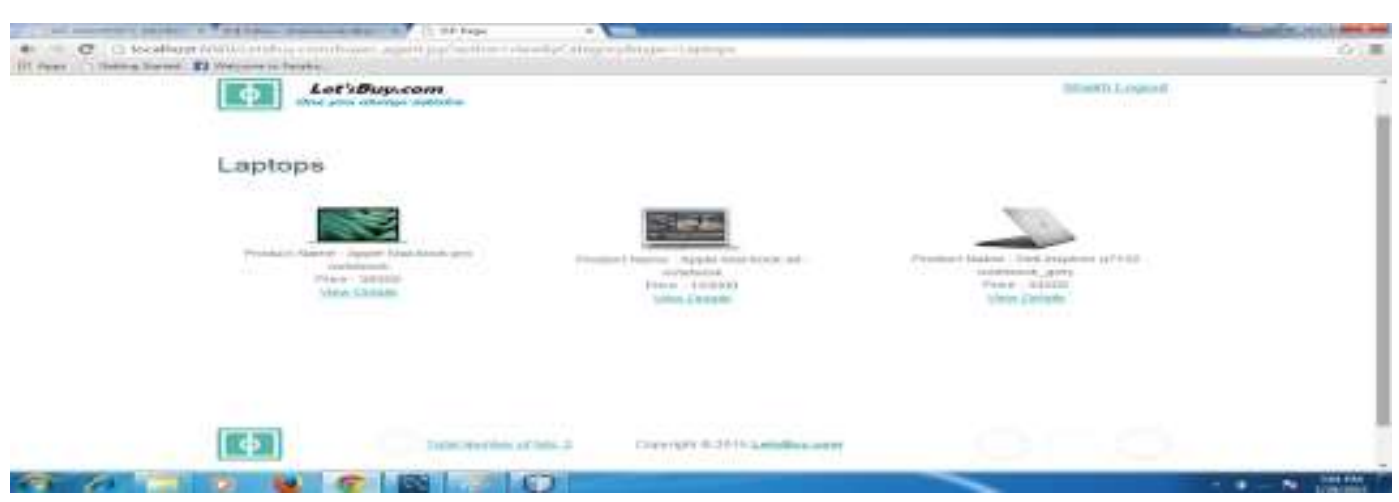

Figure 6. Laptops with Specifications

Figure 6 discusses the specifications of selected product. Selecting the category of product as Laptops, the various brands of Laptops will be available on the website with details such as Product Name and its Price. To know some more information, Click on View Details. 


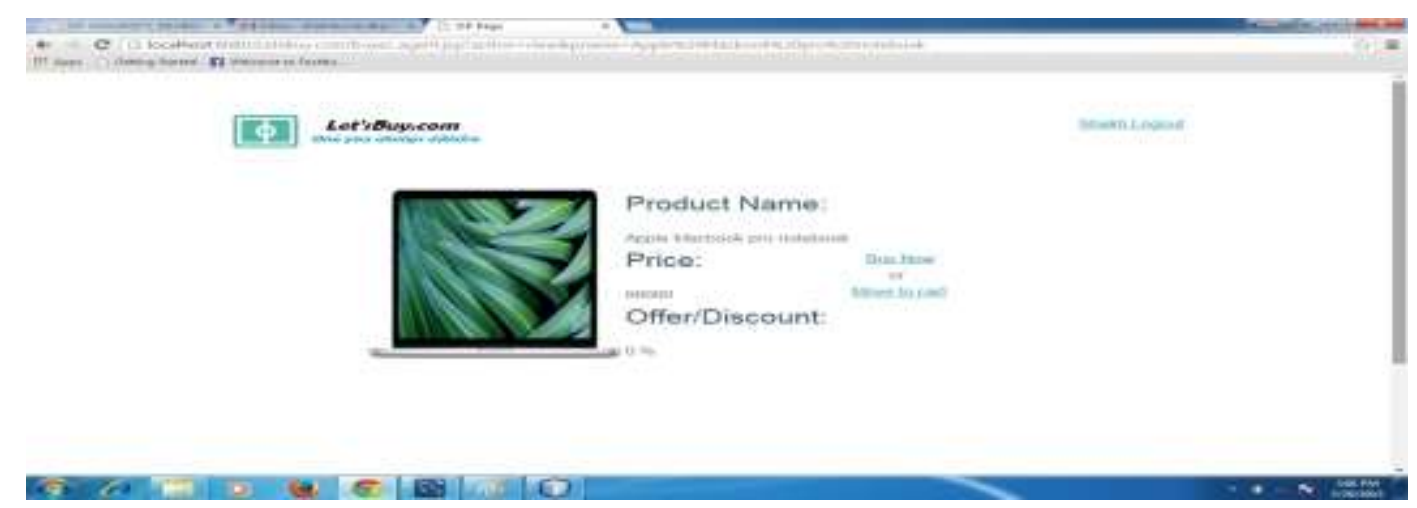

Figure 7. Screenshot Highlighting the Buying Laptop Details

Figure 7 discusses the details of buying laptop. Once you select the product of your choice for buying, the interface will highlight the next webpage with an option either Buy Now or Move to cart.

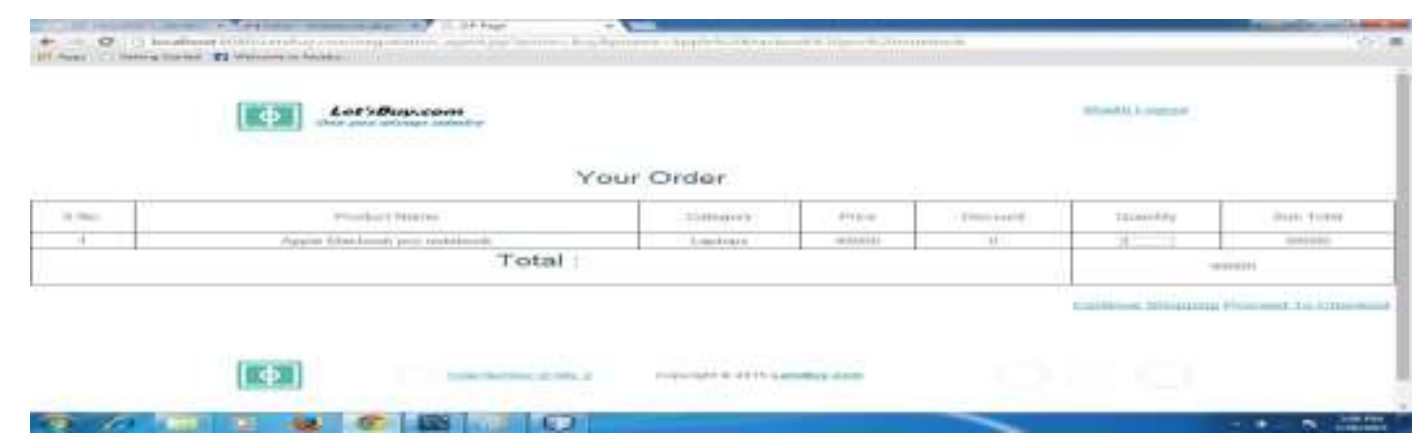

Figure 8. Order Details

Figure 8 discusses the order details. On selection an option Buy Now, the interface will highlight the Your Order summary as Product Name, Category, Price, Discount, Quantity, Sub Total.

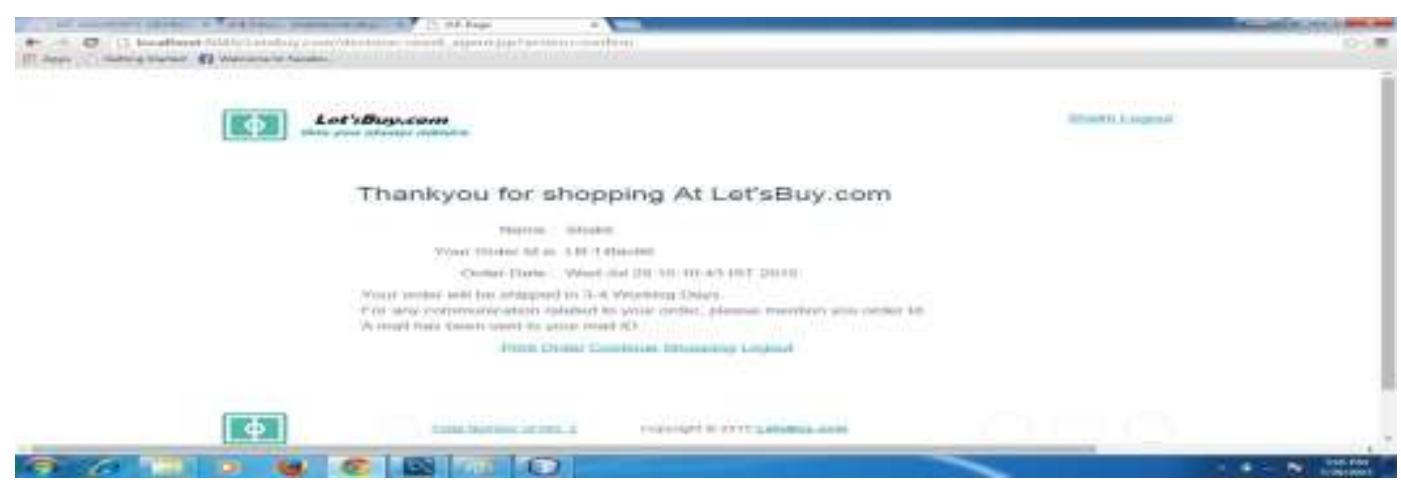

Figure 9. Confirm Order

Once you click on Proceed to Checkout, Figure 9 highlights the details of order confirmation with an acknowledgement. If you want to have an e-receipt, then click on Print Order otherwise click on Logout tab. 


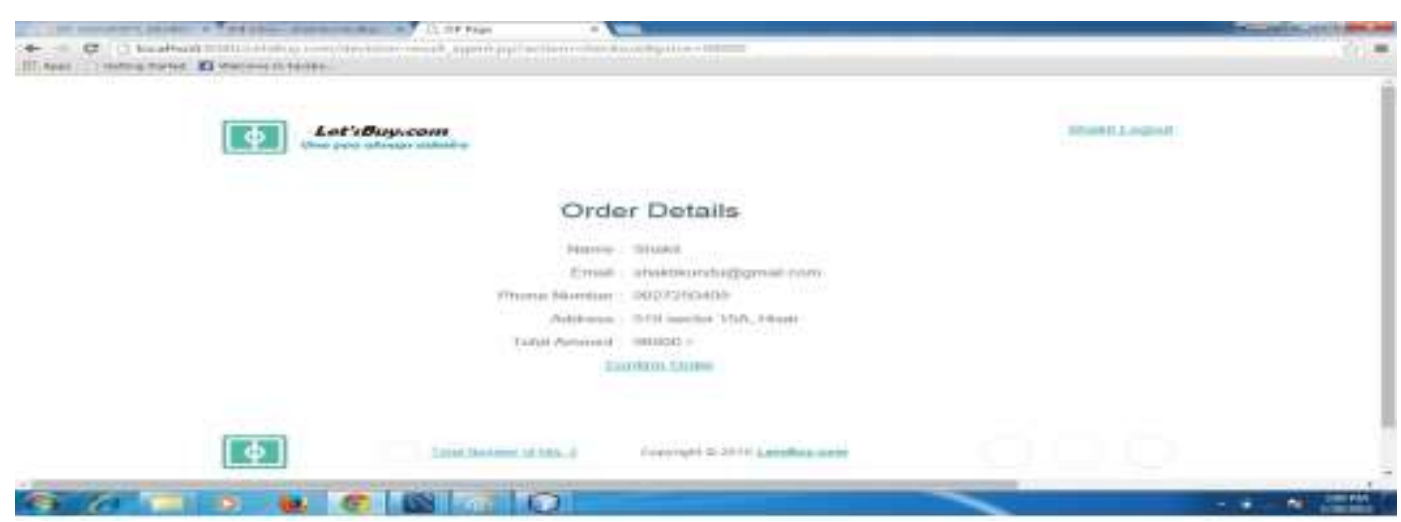

Figure 10. Proceed to Checkout as Buyer

Figure 10 highlights an e-receipt of order details. Once you click on Print Order, interface will display an e-receipt of order details such as Name, Email, Phone Number, Address, Total Amount paid.

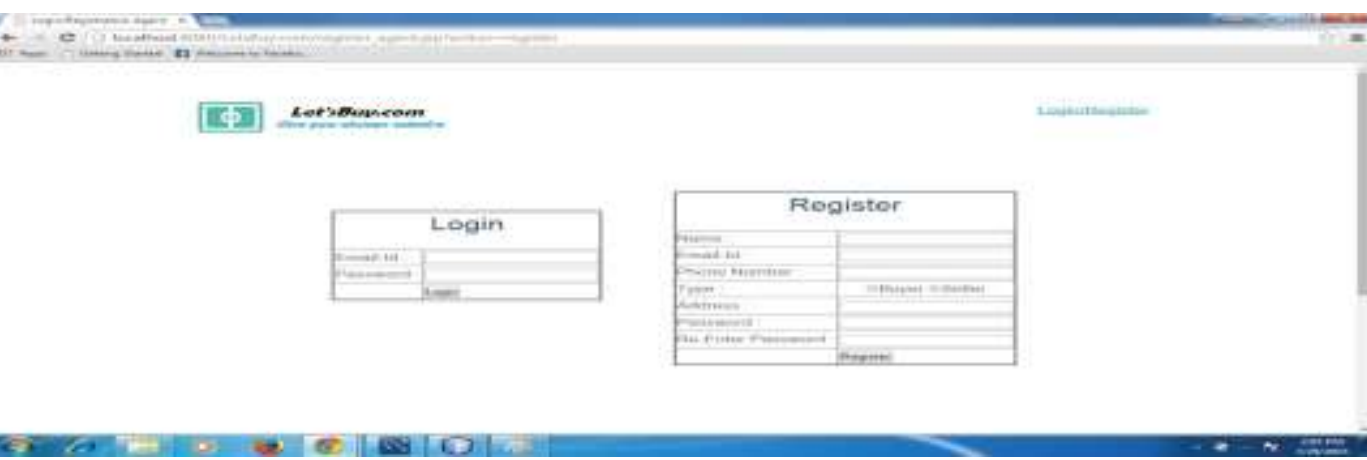

\section{Figure 11. Login and Register Screen as Seller}

Figure 11 discusses the Login and Register screen as Seller. For the first time visit, Seller has to register while filling the form available on the website and then Seller will be able to Login with their respective Email-Id and password.

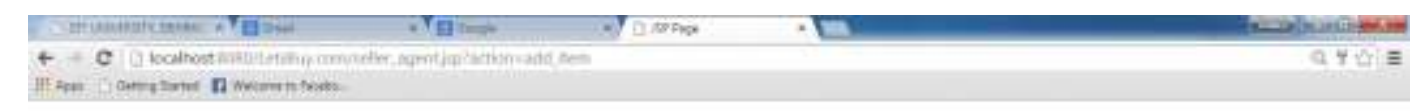

[5] Letiogren.

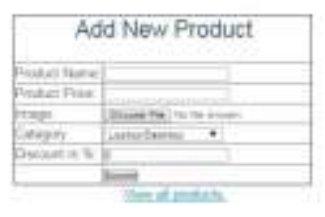

Figure 12. Add New Product as Seller

Figure 12 discusses the screen of Add New Product as Seller. Once the Seller login into the website, he can view all the details of products by clicking on View all products tab. Moreover, the seller can extend his list of products by clicking on Add New Product tab with details such as Product Name, Product Price, Image of product, Category and 
Discount. When all the respective details had been filled in the form by the Seller, then finally click on Submit button.

\section{The Back End Interface of Web Mining Intelligent Agents (WEBMINTEL) System}

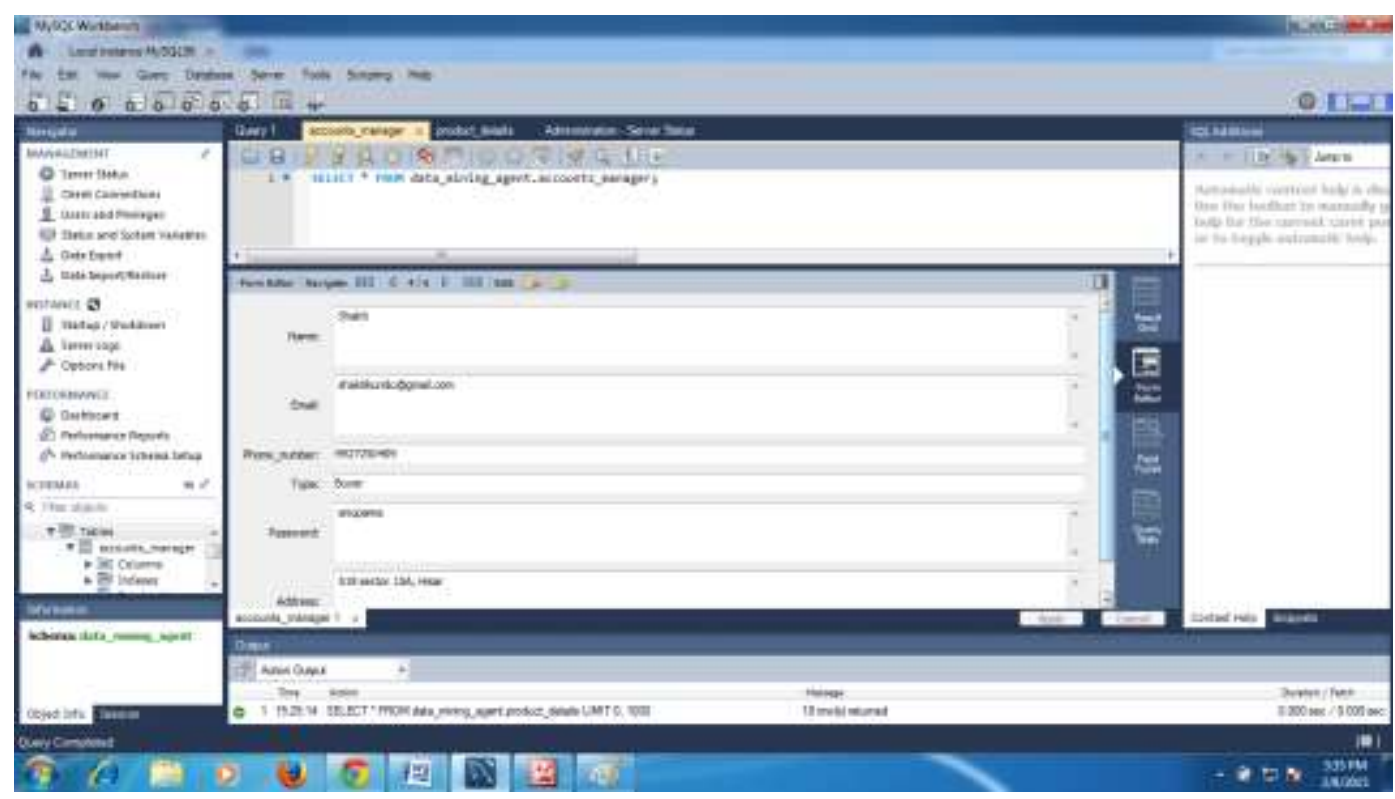

Figure 13. Data Mining Agent Accounts Manager Form Editor

The back end interface of WEBMINTEL System worked on MySQL. Figure 13 discusses the screenshot highlighting the form editing activities done by Data Mining Agent Account Manager with the following query:

SELECT $*$ from data_mining_agent. Accounts_manager;

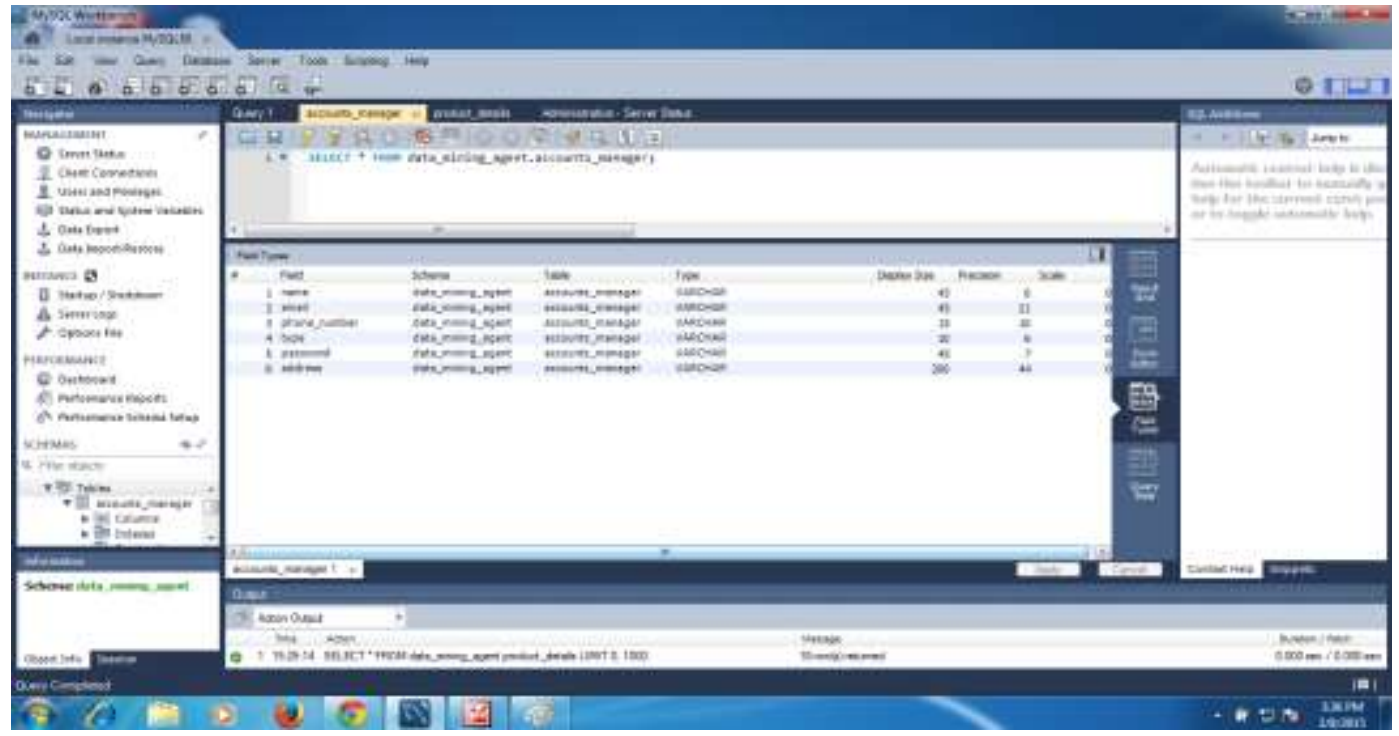

Figure 14. Data Mining Agent Accounts Manager Field Types 
Figure 14 discusses the creation of Field Types by Data Mining Agent Accounts Manager. The various fields such as name, email, phone_number, type, password, address were managed by Data Mining Agent.

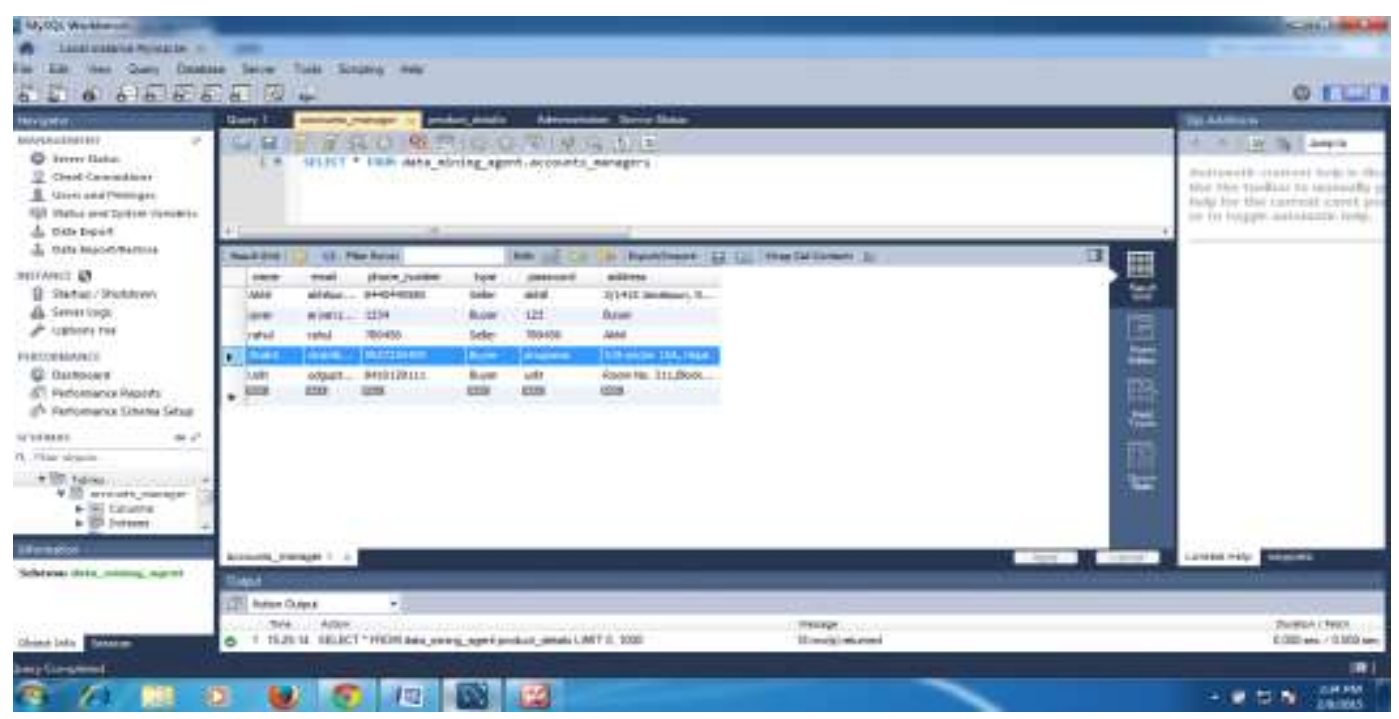

Figure 15. Data Mining Agent Accounts Manager Result Grid

Figure 15 discusses the setup of Result Grid by Data Mining Agent. As soon as number of visits to website increases, the length of Result Grid increases with the respective Field Type details which was managed by Data Mining Agent Accounts Manager.

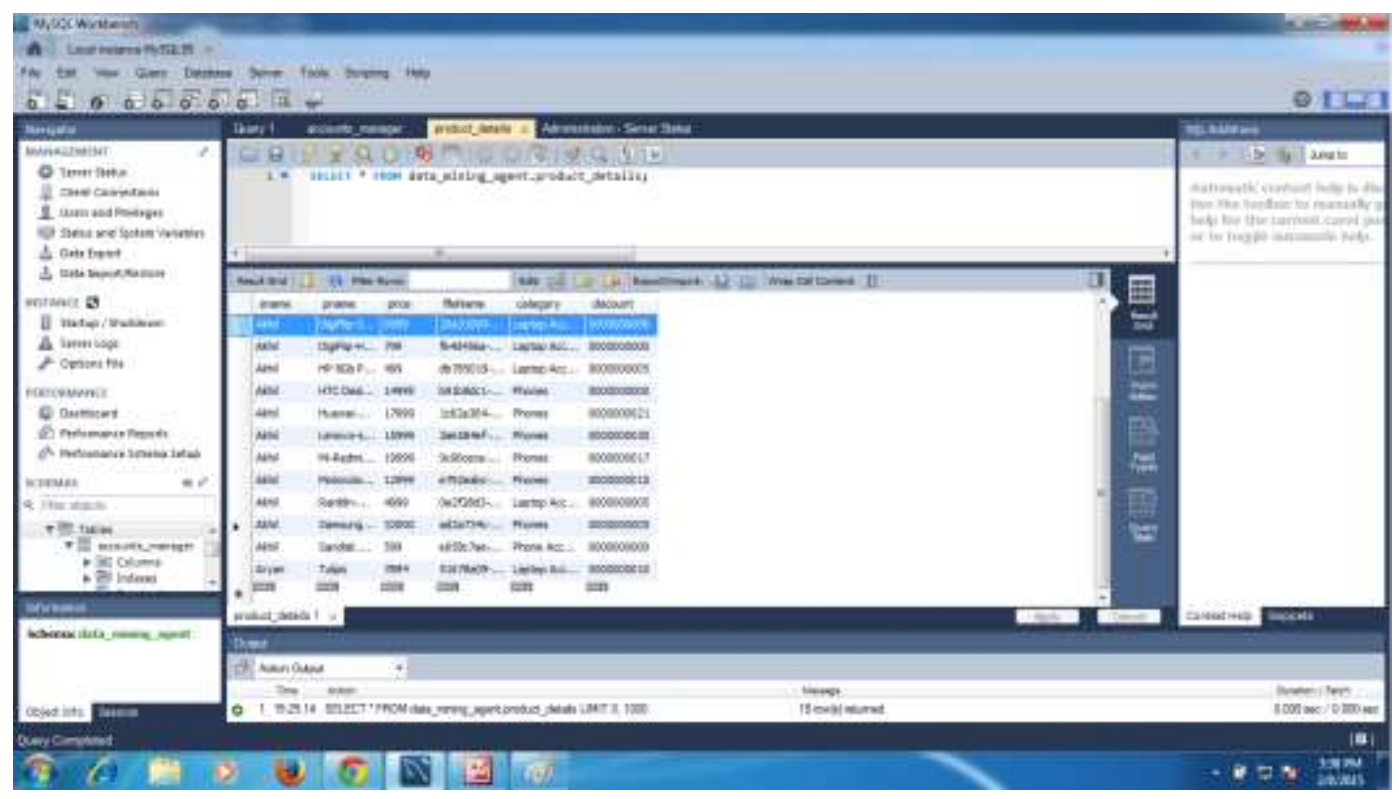

Figure 16. Data Mining Agent Product Details Result Grid

Data Mining Agent manages information of product details such as Seller name, Product name, Price, Filename, Category and Discount. Figure 16 discusses the screenshot highlighting setup of Result Grid of Product Details by Data Mining Agent Product Details with the following query:

SELECT * from data_mining_agent.product_details; 


\section{Conclusions}

Due to the explosive growth of web content in the internet world in the past few years, there is tremendous requirement and scope of doing research in the category of Ecommerce Agents. Also user requirements such as getting accurate information in a prompt manner are not getting fulfilled as per their expectations. With Java Application Development Environment and WEBMINTEL System, it becomes easier to implement Agents. The proposed work is to make the Web Data Mining system more efficient and intelligent.

\section{References}

[1] The IBM Agent, Available: http://www 03.ibm.com/systems/director/downloads/agents.html, Accessed: (2016) October 9.

[2] M. Chajri and M. Fakir, "Application of Data Mining in E-commerce", Journal of Information Technology Research, IGI Publication US, vol. 7, no. 4, (2014), pp. 79-91.

[3] Q. Han, X. Gao and W. Wu, "Study on Web Mining Algorithm based on Usage Mining", Proceedings of $9^{\text {th }}$ International Conference on Computer Aided Industrial Design and Conceptual Design, IEEE Xplore, (2008).

[4] Q. Cen, J. Zhao and X. Zhu, "The Data Mining System based on Multi-Agent under the circumstances of E-commerce", Proceedings of $3^{\text {rd }}$ International Conference on Natural Computing (ICNC 2007) IEEE, (2007), pp. 34-38.

[5] I. Tudor and L. Ionita, "Intelligent Agents as Data Mining Techniques used in Academic Environment", Proceedings of $4^{\text {th }}$ International Conference on Virtual Learning ICVL, (2009), pp. 380-384.

[6] Q. Tang and F. Xie, "Agent Based Negotiation Model for E-Commerce", Wireless Communications, Networking and Mobile Computing, Proceedings of WiCom, International Conference, (2007), pp. 3466-3469.

[7] Y. Tang, X. Liu, Y. Huang and G. Lu, "The Design of Data Mining System”, Theory and application of System Project, (2000), pp. 56-63.

[8] A. T. Siddiqui and S. Aljahdali, "Web Mining Techniques in E-commerce Applications", International Journal of Computer Applications, vol. 69, no. 8, (2013), pp. 39-43.

[9] I. Dzitac and I. Moisil, "Advanced AI Techniques for Web Mining", Proceeding of the 10th WSEAS International conference on Mathematical methods, Computational Techniques and Intelligent Systems (MAMECTIS'08), (2008), pp. 343-346.

[10] W. C. Hu, X. Zong, C. W. Lee and J. H. Yeh, "World Wide Web Usage Mining Systems and Technologies", International Journal of Systemics, Cybernetics and Informatics, vol. 1, no. 4, (2003), pp. 53-59.

[11] J. Srivastava, R. Cooley, M. Deshpande and P. N. Tan, "Web Usage Mining: Discovery and Applications of Usage Patterns from Web Data", SIGKDD Explorations, vol. 1, no. 2, (2000), pp. 12-23.

[12] J. Liu and R. Datla, "Web Usage Mining - Pattern Discovery and its Applications", Available: http://slidegur.com/doc/3917477/web-usage-mining---pattern-discovery-and-its-applications, Accessed: (2016) November 18.

[13] H. Baazaoui Zghal, S. Faiz and H. Ben Ghezala, "A Framework for data mining based multi-agent: An application to spatial data", World Academy of Science, Engineering and Technology, International Journal of Computer, Electrical, Automation, Control and Information Engineering, vol. 1, no. 5, (2007), pp. 1410-1414.

[14] L. Mei and F. Cheng, "Overview of web mining technology and its application in e-commerce", Proceedings of $2^{\text {nd }}$ International Conference on Computer Engineering and Technology, IEEE Explore, vol. 7, (2010), pp. 277-280.

[15] N. Goel and C. K. Jha, "Analyzing users behavior from web access logs using automated log analyzer tool”, International Journal of Computer Applications, vol. 62, no. 2, (2013), pp. 29-33. 


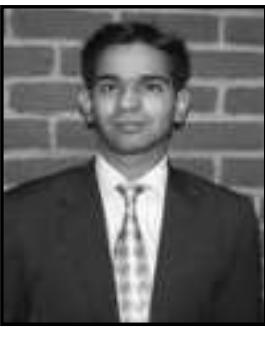

\section{Authors}

Shakti Kundu, He received his M.Tech. in Computer Science \& Engineering from Guru Jambheshwar University of Science \& Technology, Hisar, Haryana, India in 2010, M.Phil. in Computer Science from Chaudhary Devi Lal University, Sirsa, Haryana, India in 2008, M.C.A. from Kurukshetra University Kurukshetra, Haryana, India in 2006. Presently he is pursuing his Ph.D in CSE from DIT University, Dehradun, India. The author current research interests are Web Mining, Knowledge Management and Web Testing. He is life member of CSI, ISTE, IAENG, AIRCC and IAEME.

M L Garg, presently Professor and Head, Department of Computer Science \& Engineering at DIT University, Dehradun, India, has obtained his Ph.D degree in Computer Science \& Engineering from Thapar Institute of Engineering \& Technology (Deemed University), Patiala, India with collaborative research work at IIT Delhi, in the year 1992. He has a total experience of about 37 years out of which 16 years is in academics and 21 years is in Punjab State Electricity Board. Three researchers have completed and 4 others are pursuing their Ph.D under his supervision. He has been the Dean Faculty of Engineering for a period of 5 years at Shri Mata Vaishno Devi University, Katra, India. His area of research includes Fuzzy Logic Genetic Algorithms \& Knowledge Representation and Reasoning. He has published about thirty research articles in peer reviewed International and National Journals and Conferences. He is on the Editorial Board of the International Journal of Cloud Computing and Super Computing (IJCS), Canada. 
International Journal of Advanced Science and Technology Vol.104 (2017) 